\title{
Assessing Pacemaker Patients' Perception of Lifestyle: After an Educational Intervention
}

\author{
Ghulam Kubra Khaliq ${ }^{1}$, Fariha Hasan Rehan², Faisal Qadir ${ }^{1}$, Abdul Mueed', \\ Zubair Mumtaz', Ghazala Irfan', Azam Shafquat ${ }^{1}$
}

\begin{abstract}
1. Department of electrophysiology, NICVD, Karachi.

2. Department of adult cardiology, NICVD, Karachi.
\end{abstract}

\section{Address for Correspondence:}

Kubra Khaliq

Department of electrophysiology, NICVD, Karachi..

Emails: ghulam.kubra@nicvd.org

All authors declare no conflict of interest.

This article may be cited as: Khaliq GK, Fariha Rehan FH, Qadir F, Mueed A, Mumtaz Z, Irfan G, Shafquat A. Assessing Pacemaker Patients' Perception of Lifestyle: After an Educational Intervention. Pak Heart J 2020;53(01):99-99. https://doi.org/10.47144/phj.v53i1.1918
Objectives: Misconceptions regarding various physical activities after pacemaker implantation can severely limit a patient's lifestyle and very little in terms of patient education has been done to correct it. This study; by means of both verbal, and provision of brochure for education of patients; at the time of discharge and then reinforcing by questioning again at subsequent visit, aims to correct it.

Methodology: A Quasi- experimental design of study carried out on consecutive patients implanted permanent pacemaker at electrophysiology department NICVD Karachi. Patients were discharged with an educational brochure and practical application of various daily life activities after assessment of related knowledge at baseline with reassessment at 1 st visit. A questionnaire of 25 daily activities was developed and tested. Patients perception of safety of various daily activities both at baseline and at 1 week follow up were noted along with socio- demographic data of the patient.

Results: A total of128 patients were interviewed at baseline, out of which 115 showed up for follow-up after one week. Male patients were $59.4 \%(76)$ of the sample and $47.7 \%$ were illiterate. Mean age of the patient was $60.31 \pm 12.81$ years. Only 11/128 at baseline, and 59/115 after intervention, answered all questions correctly. The percentages at baseline and 1 week follow up for: driving ( $82 \%$ vs. $99.1 \% ; p=0.005)$, climbing stairs (75\% vs. $97.4 \% ; p<0.001)$, sleeping on the side of pacemaker ( $60.2 \%$ vs. $91.3 \% ; p=0.001)$, usage of mobile phone ( $28.1 \%$ vs. $96.5 \%$; $p<0.001)$, for electric iron ( $54.7 \%$ vs. $94.8 \%$; $p<0.001$ ), electrical switches $(16.4 \%$ vs. $96.5 \%$; $p<0.001)$, microwave ovens $(54.7 \%$ vs. $84.3 \% ; p<0.001)$, electrical sewing machines (58.6\% vs. $93.0 \% ; p=0.106)$, UPS and electricity generators $(52.3 \%$ vs. $87.8 \% ; p=0.003)$, electric motors (63.3\% vs. $91.3 \%$; $p<0.001)$, undergoing X-Ray irradiation (68\% vs. $96.5 \%$; $p<0.001)$, and ultrasound imaging (65.6\% vs. $93.9 \% ; p=0.005)$.

Conclusion: Many pacemaker patients' misperception leading to unnecessarily restricted lifestyle can be corrected by simple measures such as distribution of brochures and in hospital implementation of those activities which can be resumed with in hospital stay thereby benefitting the patient more than just with implantation. Distribution of these brochures and counseling with practical application should therefore be standardized and made as part of routine for all pacemaker patients.

Keywords: mobile phone usage $1, \mathrm{MRI}$ scanning 2 , patient education 3 , permanent pacemaker 4. 